investor in scemities." Deze schrijver luegint met op te merken, dat de bezitter ran aandeclen als helanghebbende bij hot wit te kereen dividend mecr anudacht behoorde te besteden anm de winst en aan de winstluron. Hicr'na behandelt hịj eer'st den juridischen kant ran de afselnrijvingen als middel, om de winstbrou intact te houden. Warbij blijkt, dat in Engeland re naamloozo vennootschappen in lict algemeen rij zijn, om in hun statuteri de regeling ten aanzien ran de opstelling der winstrekening c!r de bepaling van winst en winstuitkeering vast te Jeggen, zooals ze zolf verkiezen. I) Engelsche wet en jurisprudentic laten hierin een vons onze hegrippen tamelijk groote vrijheid: Ben vemnootschap, welke ecnige jaren verliezen geleden heeft, mag in een daarop volgend gunstig jadr, indien de liquiditeitspositic het toclaat. tot winstuitkeering overgaan, zonder dat ecrst hot. aandeclenkaptaal weer intact hoctt te zijn. Fen maatsehappij met en afloopende concessie of met andere bezittingen, wélke uit har aard langzamerhand uitgeput raken (mijnen br.) mag ook dividenden uitkeeren, weliswant zoodanigr dat haar liquiditeitstoestand geen geval' loopt, doch zondel' verplicht te ziju te zorgen voor een reserve, warmee ze na afloop een nieuw. soortgelijk bedrijf kan beginnen.

Komende tot de afschrijvingen, latat Sir William Plender. blijken, weinig te willen weten van vaste regelen, waarnaar dezc zouden moeten geschieden. IIij behandelt dus de gevallen meer of mindel opportunistisch, doch komt meestal intuïtief tot een geslaugdc oplossing. Voor spoorwegen, gas- en electriciteitsondernemingen e.d. billijk hij de rermijding van een afschrijvingsreserve, acht het geoorloofd, dat de winstrekening pas: wordt belast op het tijdstip, dat eenig activum vervangen moet worden, zoodat de winstrekening dus wordt geflatteerd in de cerste jar'en van het bestaan van de onderneming, als er nog geen vernicuwingen noodzakelijk zijn en zwaar wordt belast in den tijd, dat deelen gererrareerd of vervangen moeten worden. Bij $L$. R. Fash vonden wij dezelfde motiveering leiden tot een „voorzichtige" formule, waarin de afschrịiving in verband werd gebracht met de bedrijfsdrukte.

Tenslotte behandelt Sir William Plender het geval, dat de l'eproductickosten van een activum den aanschaffingsprịjs overtreffen. In dit geval wil hij gedurende den levensduur van de desbetreffende bezitting toch niet meer dan den aanschaffingsprijs ten laste van de winstrekening brengen. De argumenten hiervoor zijn echter een weinig naïef en o.i. niet houdbaar.

Hetzelfile probleem, dat Plender aan het slot van zijn referaat even aanrakkt, wordt nitvoeriger doch evenmin bevrechlgend behandeld door John R. Wildman als ," )epreciation and obsolescence as affected by appraisals." Ook deze inleider wil bij prijisverhooging geen afschrijvingsreserve vormen, hoog^r dan den oolsplonkelijken aanschaffingsprijs, waarbij hij in de eerste plaats uitgaat van het principe, dat de onderneming geroepen is, om haar nominaal kapitaal intact te houden, doch niet, on den verstrekkers van lang crediet dezelfde koopkracht terug te geven als ze van deze te leen ontving. Het ontkennen van een dergelijke verplichting door dezen inleider doct wat vreemd aan, als hij even later aankomt met het toch óók ethische argument, dat de consumenten beschermd moeten worden tegen een prijsverhooging, welke het gevolg zou zijn van een risicopremie tegen wardevermindering van de munt, welke in de afschrijvingen verwerkt zou worden.

De practijk wil eenigszins anders: de ondernemer zal in de gunstige jaren - welke in het algemeen met de bedoelde prijsverhoogingen gepanrd gaan — zijn zaak zoo sterk mogolijk willen maken, en ook theoretiseh is hier alles voor to zeggen, zooals het referaat van prof. Polak leert.

Dr. Werner Grull nocmt zijn referaat „Iepreciation and obsolescence as affected by the post-war reorganization of industry". Hij behandelt, na de rerschillende vormen van ratio- nalisatic besprohen te hebben, vnl. de vraag, in hoeverre de kosten aan de jationalisatic van een ondememing verbonden, ten laste ram én jaar moeten worden gebracht of verdeeld mogen worden. De meeste van dergelijke kosten meent hij to moeten besehouwen als middelen. waardoor de bestaande organisatic beter voor het producticproces geschikt wordt gemaakt. zoodat ze geen additioncele belegging vormen. M.a.w. deze uit. gaven mocten noodzakelijk geacht worden, om het bedrijf ,,konkurrenzfähig" te houden, zoodat men ze wel niet in den kostprijs zal kumnen verwerken, wat overigens nog niet wil zeggen, dat deze kosten in ćn jaar ten laste van de winstrekening go. bracht mocten worden. 1)e bedoeling is voornamelijk, om op het belang van de boschouwing van dergelijlie factoren ten opzichte ran den kostprijs - noodig o.a, voor de waardeering vas: halffabrikaten - te wijzen.

Van alle afschrijvingsreferaten van het Internationaal Accountantscongres zal zonder twijfel dat van prof Polal: "Theories of depreciation" de meeste aandacht trekken, zoowel van theoretici om de wịze ran bchandelen — welke aansluit bij die van het in 1924 verschenen Economistartikel „Waardeerings- en balansproblemen" - als van menschen uit de practijk, die in de nitkomsten hun opvattingen bevestigd zien Daar het referaat intusschen door opname in het ,MIaandblad voor het Boekhouden" voor iedereen toegankelijk is gemaakt, zullen wij er hier niet verder op in gaan.

Het laatste referaat, dat over afschrijvingen is uitgebracht, behandelt nog speciaal de afschrijving als kostprijsfactor (Carl (r. Jensen: Depreciation and obsolescence as related to cost of production). Blijkbaar waren er nog accountants, die er aail twijfelden, of normale afsehrijvingen in kostprijsberekeninger moeten worden opgenomen; voor hen is het betoog van Jensen geschreven.

Ook deze inleider toont zich tegenstander van het systeem, om bij prijjstijging een afschrijvingsreserve te vormen, waaruit de aanschaffing ran cen nieuw activum ten volle bestreden kin worden.

Blijken dus niet alle referaten van het Derde Internationale Accountantscongres even verdienstelijk, we moeten niet vergeten, dat de leiding er in elk geval in geslaagd is, om het afschrjjvingsproblem van zees verschillende zijden te doen be lichten.

Drs. A. MEIJER

\section{ELIMINATIE VAN DEN SEIZOEN-INVLOED UIT DE STATISTIEK DER VERKOOPEN}

In een vorig opstel, handelende over economische rationalisatie, werd aangekondigd, dat een greep zon gedaan worden uit de statistiek der onderneming.

Daaruit zou moeten blịkell het belang en de toepasbaarheid van moderne statistiek-methoden voor het „New Management".

Om dit te demonstreeren nemen wij als voorbeeld de statistiek der verkoopen. Wanncer men uit deze statistiek de tendenz wil leeren kennen, łan moeten die invloeden geëlimineerd worden, die storend werken en het beeld vertroebelen. Het meest vool de liand liggend is dan, wamneer het bedrijf seizoen-activiteit ${ }^{1}$ ) keut, dezc allereerst uit te schakelen. De methoden, die hierbij gebruikt kumen worden, rormen het onderwerp van dit opstel.

Ilet opstellen van seizoenindices kan echter ook ..Selbst"zweck" zijn. In het algemeen wordt door de schrijver's het eerste doel teveel op den voorgrond gesteld. Schäfer (, Marktbeob-

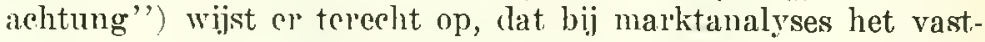

1) Zie tabel I aangevende de seizoen's activiteit in verschillende hedrijfstakken in de U. S. A. (ontleend aan White, Market analysis). 


\section{SEIZOEN'S ACTIVITEIT}

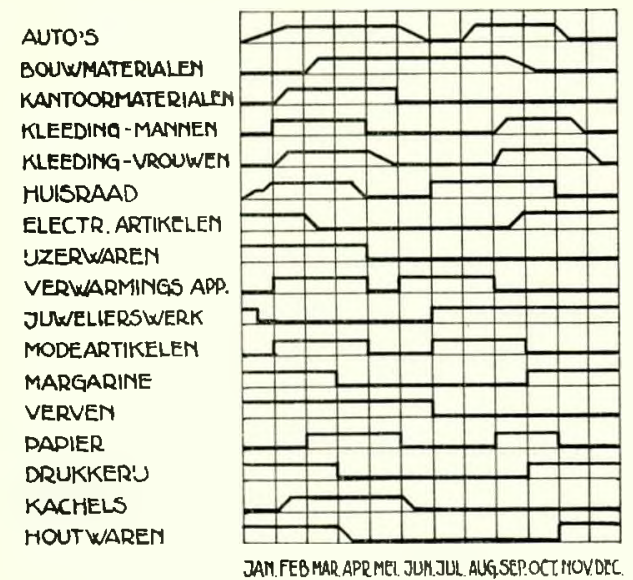

TABEL 1

stellen der seizocuschommeling zelf het doel is. Men wil b.r. de seizoenvariaties kennen van cen bepaalde groep klanten van de onderneming, om zooloende een grondslag te krijgen roor de verkoop en prijspolitick te humen opzichte.

Welk doel men ook voor oogen heeft, de methoden ziju hetzelfde; in dit opstel wolden ze gedemonstreerd aan de hand van verkoopeijfers.

Tot de voortreffelijke publicaties van het Institut fïr kionjunkturfor'schung behoort ook een reeks ,,Sonderheften'”. IIierin verseheen een werk van Donner over de methoden ran elimi- natie van seizoeninvloeden, zooals deze door versehillende onderzockers worden toegepast.

Het is niet de bedocling in clit opstel deze materio opmienw in alle volledigheid to behandelen; hicrvoos rewijzen wij belangstellenden natr dit voortreffelijke werk.

Wel willen wij de alandacht vestigen op die methoden, dic ook vor het onderzoek mar tendenzen in te ondorneming van be I.: ng lijken. Dic methoden zijn:

1. . de methode der mandgemiddelden;

20. de ,Link relatives method" ;

$5 \circ$. de methode der ,moving arerages".

Deze methoden zullen wij achtereenvolgens behandelen.

Zij berusten alle op het principe uit eijfers ran meerdere jiren indices te berckenen, die een gemiddeld of ,nomual" scizoen-verloop karakterisecren. / /ij onderscheiden zich slechts in graad vas nauwkeurighcid.

De methode der matudyeniddolden. 'T'eneinde de scizoenschommelingen met eenige zokerheid te kumnen bepalen is het licodzakelijk, ejjfers over cen reeks van jaren to veryamelen. Wanneer de seizoeneyclus van een sterk geprononecerd karalkter is, kan men met minder jaren volstaau en darvan een seizocn index berekenen, die eveneens te gebruiken is.

Deutsch demonstreert in zijn werk (,Konjunktur und ['nternehmung") de bruikbaarheid der verschillende methoden an de hand van de maandomzeteijfers der Wallworth Company. medegedeeld door Barber in ,Budgeting to the Business ('ycle". Wij zullen dezelfde eijfers tot grondslag nuemen voor rnze uiteenzetting.

PERIODOGRAM OPGESTELD TER BEREKENING DER SEIZOENINDICES NAAR DE METHODE DER MAAMDGEMIDDELDEN.

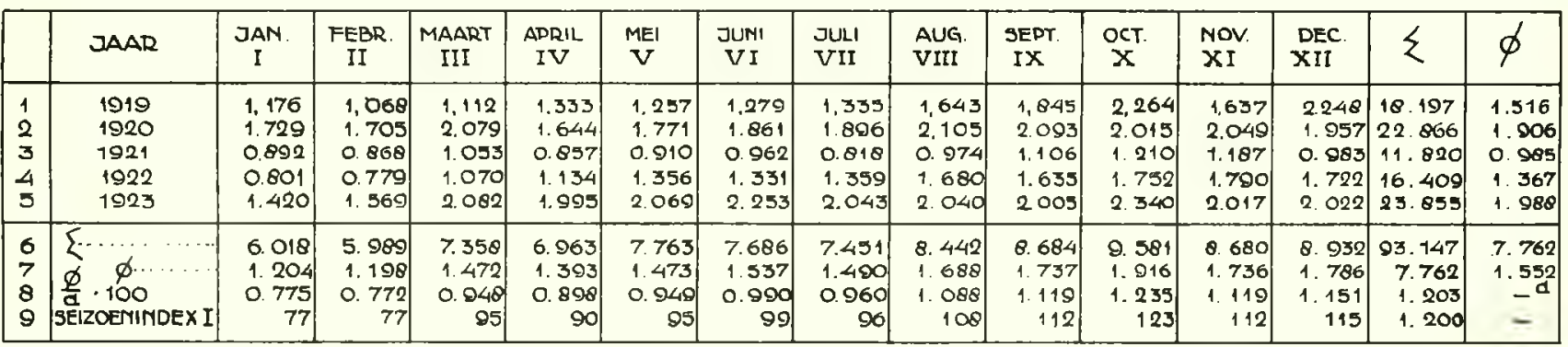

BEREKENING VAN DE SEIZOENINDICES ONDER UITSCHAKELING DER TREND-INVLOED.

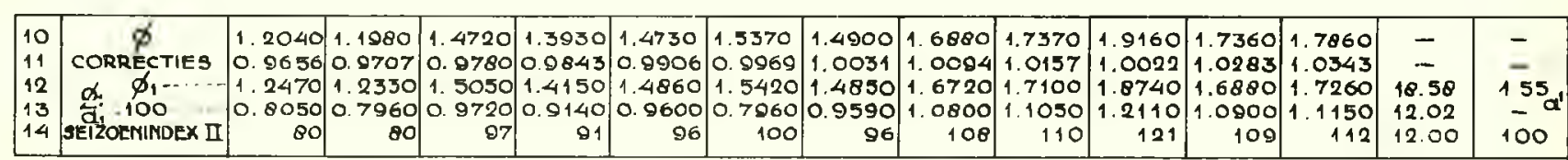

De lezer gelieve eerst het periodogram (tabel 2 ) te bestudeeren, dat hierboven is afgedrukt. 11ij ziet dan, dat over een periode van $\bar{j}$ jaar de rerschillende maandomzetten dusdanig zijn gegroepeesd, dat op eenvondige wijze de mandgemiddelden zijin te berekenen.

Het cijfer, afgedrukt bij a. is het algemeen mandgemicldelde over de periode van 5 jar berekend.

Wanneer men de gemiddolde maandomzotten uitdrukt in proeenten ran liet algemon manndgemiddelde, dan kijijgt men indiecs, die de basis ropnen der berokening van den sei\%ocnindex. Wannecr men deze eijfers af rondt, watrbij het totalal op 1200 is te brengen krijgt men den seizoenindex.

Bestant een duidelijk merkbal' 'Trend ${ }^{2}$ ) dan dient deze uitgeschakeld te worden. Vertoonen de verkoopen een aceres, dau is de Decemberomzet altjjd looger dan de Januari-omzet van dat jaar en dat. wol zooveel, als het acress in de 11 tusschen-

\footnotetext{
1) Trend $=$ algemeene richtlijn.
}

manden bedraagt. Het gevolg daarvan is, dat de loorsucde van alle Decembercijfers in verhouding tot de Januali-eijfers overdreven is.

llet omgekeerde is het geval bij decres. Wil men dus een zuiveren seizoenindex berekenen, dan moet de 'T'rendinsloed geclinincerd worden.

De invloed der ('onjunctuur op de herekende seizonnindies kan buiten beschouwing worken gelaten, daar door meerdere jaren te nemen in de madndgemiddelden do romjunctumbheweringen zich min of meer compensecren.

Bij de Trend-eorrectio in het voorloedd wordt verondersteld. wat de algemeene ontwikkeling van de onderneming gelijkmatig en rechtlịnig kan worden voolgesteld. (Over de beschomwde periode hedraagt het aceres $1,988-1,516$, d,i. por jaar $1 / 4$ deel of 0,118 , d.i. het versehil tussehen het jaalugemildeldu van het aanvangsjat en liet laatste jarr gedeeld door het aantal heschouwde jaren minus 1. 
Wanneer: wij dus 0,118 in procenten van het algemeen jaalgemiddelde uithlukken, krijgen wij cen waarde van $0,11.8: 1,552$ of 0.076 jer jaar, d.i. 0,00633 per mand. (Trend-waarde)

Hot behulp van dit laatste gretal kumen wij de Trendcolrectic ambrengen, Danrvoor verdeelen wij de getallenrij in tweëin. In de cerste helft wordt ter vorming van de correctiefictoren de in een procent van het algemeen jaargeniddelde nitgedrukte T'rendwaarde van het getal 1 afgetrokken, in de tweede helft bij het getal 1 opgeteld (d.w.\%. bij stijgende Trend; bij dialende Trend omgekeerd).

De telling van de naanden wordt in het midden ran het jaar hegonnen; aan de eerste maand wordt $1 / 2$, aan de tweede maand $1 \frac{1}{22}$ en aan de derde maand $21 \%$, $>$ mandel. Trendwaarde toegeroegd (respe, afgetrokken).

Dat men bij den aanvang slechts $1 / 2 \times$ maandel. Trendwatrde moct optellen, resp. aftrekken, is daaruit te verklaren. cat het midden van het jaal op 1 .Juli valt en de middenwaarde van de ecrste manden 15 dagen later of vroeger valt. Daarom is dit punt van het midden niet een hecle, maar slechts een laalve mand verwijderd.

De deeling van de mandgeniddelden roor de daaronder staunde colrectie-factoren geeft als resultaat de gecorrigeerde gemiddelden, die samen 18,58 bedragen en waruit het rekenkundig gemiddelde 1,55 bedraagt.

Deze gecorrigeerde maandgemiddelden, uitgedrukt in procenten van het gecorrigeerde algemeen geniddelde $\|_{1}$ geven als resultaat de seizomindices onder nitschakeling van den Trendinvloed.

\section{MAAND - VERKOOP}

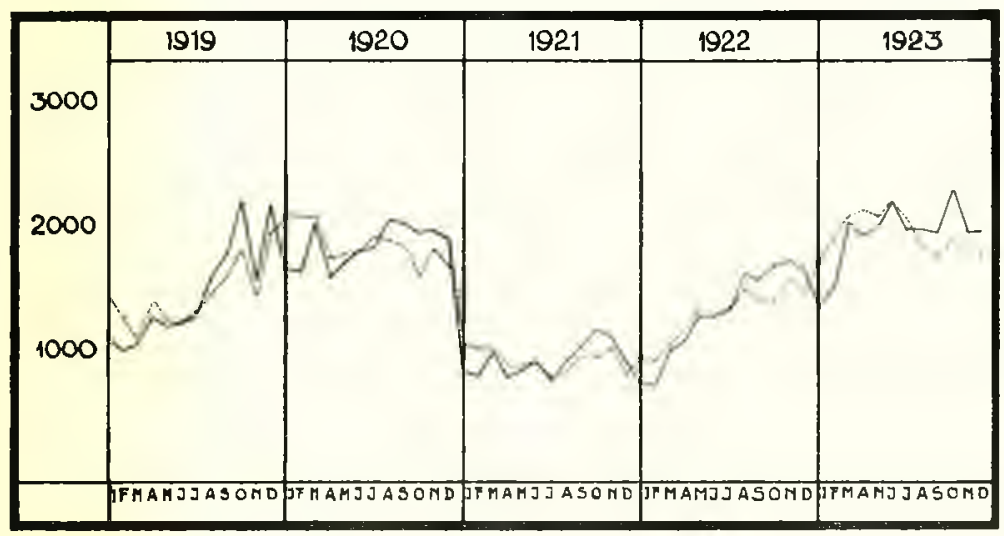

SEIZOEN - SCHOMMELING

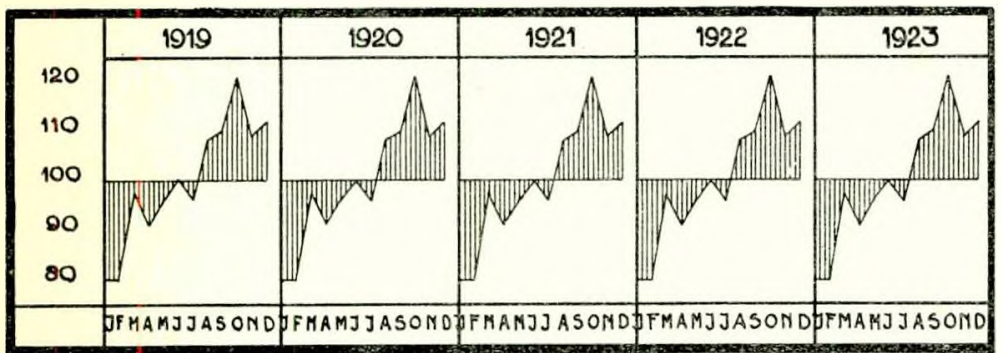

MAAND - VERKOOD

MAAND-VERKOOD ONDER ELIMINATIE $Y / D$. SEIZOEN-SCHOMMELING

In tabel 3 is in beeld gebracht:

$1^{\circ}$. de maandverkoopen.

20. de mandrerlioopen onder. eliminatic der. seizonsehommelingen.

$3^{\circ}$. de scizocruschommelingen.

Ilieruit blijkt de nitgesproken seizoenaetiviteit van het behrijt in kwestie. De rerkoopen zijn nu gezuiverd vall den seizoeninvloed en roor verdere bewerking vatbar (bijvoorbeeld bepaling van de 'Trend, waarroor eveneens bepaalde calculaticmethoden bestaan).

De methode der maandgemiddelden is volgens den Amerikalanschen statisticus King zeer goed bruikbaar, wanneer de seizoengevoeligheid in verhouding tot de conjunctuurgevoeliglieid groot is.

De tweede methode om de seizocn-beweging vast te leggen is de "link relative nethod" (Crliedziffern methode), die door Warren Persons, de bekende statisticus van het Havard-Institute, algemeene toepassing heeft gevonden.

Het I'ersons lian worden toegegeven, dat de eerste methode een tekortkoming heeft; met den conjunctuur-invloed wordt slechts ten deele rekening gelyouden. Vertoonen de onderzochte cijferreeksen '2 pieken van hoog-conjunctuur, beide malen in dezelfde mand, dan komt deze maand te hoog uit en wordt de seizoenindex voor die maand te hoog. Ook toevallige factoren spelen bij de methoden der madudgemiddelden een te groote rol.

Persons' methode ber'ust darom op een andere gedachte:

II ij berckent niet de absolute waarde, mar de verandering ran maand tot maand, d.w.z. hij stelt z.g. ,link relatives" op, wadrdoor elke maand in procenten van de warde der voormaand wordt nitgedrukt:

$$
\begin{aligned}
& \text { Jan. warde } \\
& \text { Dec. warde } \\
& \text { Febr. waarde } \\
& \text { Jan. waarde }
\end{aligned}
$$

Wij verwijzen bij onze verdere uiteenzettingen naar tabel 4.

Fier ziet nen, dat uit elke 5 Gliedziffer'n de 3 meest centrale waarden genomen worden en dat daaruit het gemiddelde wordt berekend.

Wil men komen tot het opstellen van een seizoen-index, dan moel deze walde worden uitged'ukt in procenten van de doorsmeewarde; dit gaat als volgt:

In onze tabel hevat rij $T$ dcze berekende gemiddelden (de loorsmede nit de drie centrale warden). Hieruit zijn de ,chainrelatives" te berelienen, hetwclk als volgt geschiedt: Januari houdt dezelfde waurde; de andere warden worden berekend dool' (umulatieve vermenigvuldiging.

Februari-getal $=$ Jan. warde $\times$ Febr. gemiddelde.

Maart-getal $=$ Janl. warde $X$ Febr. gemiddelde $X$ Maart gemiddelde en\%.

Ilet zal duidelijk zijn, dat het latste product eigenlijk gelijk adn 100 moet zijn. Dit is hier niet het geval en komt ook slechts zelden roor, Oorzalk: 'Trend-invloeden.

Deze Trend-invloeden moeten geälimincerd worden, hetwelk gesehiedt door het verschil, dat bestaat tusschen de laatste chain-lelitive en 100 dool: 12 te declen en van de eerste chainrilative $1 / 12$ af te trekken, ran de tweede $2 / 12$, van de derde $3 / 12$ enz. ; van de laatste $22 / 12$ van het verschil.

Tit de gecorrigeerde chain-re]atives wordt het gemiddelde $\left(a_{1}\right)$ berekend, de maanden worden in procenten daarvan uitgedrukt, waarna wij afdoende de seizoen-indices rolgens deze methode hebben bepaald.

De dorde methode is die der ,moving averages." Zij staat op lalam ran Macaulay en wordt bij voorkeur toegepast in publicaties van den Federal Reserve Board. Barber toonde haar Iruikbarheid an voor bedrijfshuishondkundige doeleinden aan de hand van omzeteijfers der Walworth Cy., die wij evencens bij onze uiteenzettingen gebruiken. 
TABEL OPGESTELD TER BEREKENING DER SEIZOEN-INDICES MAAR DE "LINK RELATIVE METHOD" VAN WARREN PERSOMS.

\begin{tabular}{|c|c|c|c|c|c|c|c|c|c|c|c|c|c|c|}
\hline & JAAR & $I / X I I$ & II $/ \mathbf{I}$ & III $/$ III & IV/III & 立/是 & SII $/$ I & प्या/प & $\mathrm{var} / \mathrm{f}$ III & $\mathrm{Ix} / \mathrm{sen}$ & $x / 1 x$ & $X I / x$ & $\mathrm{xII} / \mathrm{xI}$ & \\
\hline $\begin{array}{l}1 . \\
2 . \\
3, \\
4 . \\
5 .\end{array}$ & $\begin{array}{l}1919 \\
1920 \\
1921 \\
1922 \\
1923\end{array}$ & $\begin{array}{l}- \\
76.9 \\
45.6^{*} \\
81.5 \\
82.5 \\
72.9^{*}\end{array}$ & $\begin{array}{c}90.8 \\
08.6 \\
97.3 \\
97.3 \\
110.5 * \\
-\end{array}$ & $\begin{array}{l}104.1 \\
119.7 \\
121.3 \\
137.3 * \\
132.7 * \\
-\end{array}$ & $\begin{array}{r}119.9 \\
80.5 \\
81.4 \\
106.0 \\
95.8 \\
-\end{array}$ & $\begin{array}{c}94.3^{*} \\
107.7 \\
106.2 \\
119.6 * \\
103.7 \\
-\end{array}$ & $\begin{array}{c}101.8 \\
105.1 \\
105.7 \\
982 * \\
108.9 * \\
-\end{array}$ & $\begin{array}{c}104.4 \\
101.9 * \\
85.0 * \\
102.1 \\
90.7 \\
-\end{array}$ & $\begin{array}{c}123.1 \\
111.0 \\
190.7 * \\
123.6 \\
99.9 * \\
-\end{array}$ & $\begin{array}{c}112.3 * \\
99.4 \\
113.5 * \\
97.3 \\
98.5 \\
-\end{array}$ & $\begin{array}{c}122.7 \\
06.3 \\
109.4 \\
107.2 \\
116.7 * \\
-\end{array}$ & $\begin{array}{c}72.3 * \\
101.7 \\
98.1 \\
102.2 \\
82.2 * \\
-\end{array}$ & $\begin{array}{c}137.3^{*} \\
95.5 \\
82.8 \\
96.2 \\
1002 \\
-\end{array}$ & \\
\hline \multirow[t]{2}{*}{6.} & $\varepsilon$ & 359.4 & 494.5 & 615.2 & 483.6 & 531.5 & 519.6 & 484.1 & 648.3 & 520.9 & 552.2 & 4604 & 512.1 & \\
\hline & & $\begin{array}{c}\text { JAN. } \\
I\end{array}$ & $\begin{array}{l}\text { FEBR. } \\
\text { III }\end{array}$ & $\begin{array}{l}\text { MAART } \\
\text { III }\end{array}$ & $\begin{array}{l}\text { APRIL } \\
\text { IV }\end{array}$ & $\stackrel{\text { MEI }}{\nabla}$ & JUNI & $\begin{array}{l}\text { JULI } \\
\text { VIII }\end{array}$ & $\begin{array}{l}\text { AUG. } \\
\text { VIIL }\end{array}$ & $\begin{array}{c}\text { SEPT. } \\
\text { IX }\end{array}$ & $\begin{array}{l}\text { OCT } \\
\mathrm{I}\end{array}$ & $\begin{array}{l}\text { NOV } \\
\text { XII }\end{array}$ & $\begin{array}{l}\text { DEC. } \\
\text { XII }\end{array}$ & \\
\hline $\begin{array}{r}7 . \\
8 \\
9 \\
10 . \\
11 . \\
12 . \\
13 .\end{array}$ & 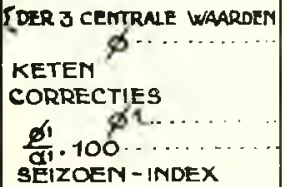 & $\begin{array}{r}240.9 \\
80.3 \\
80.3 \\
0.9 \\
79.4 \\
86.8 \\
87 .\end{array}$ & $\begin{array}{r}293.2 \\
97.7 \\
78.5 \\
1.7 \\
76.8 \\
83.9 \\
84\end{array}$ & $\begin{array}{r}345.1 \\
115.0 \\
90.3 \\
2.5 \\
87.8 \\
95.9 \\
96\end{array}$ & $\begin{array}{r}283.2 \\
94.4 \\
85.2 \\
3.4 \\
81.2 \\
89.4 \\
90\end{array}$ & $\begin{array}{r}317.6 \\
105.9 \\
90.2 \\
4.3 \\
85.9 \\
93.4 \\
93\end{array}$ & $\begin{array}{r}312.5 \\
104.2 \\
94.0 \\
5.2 \\
88.8 \\
97.0 \\
97\end{array}$ & $\begin{array}{r}294.7 \\
98.2 \\
92.3 \\
6.1 \\
86.2 \\
94.2 \\
94\end{array}$ & $\begin{array}{r}357.7 \\
119.2 \\
110.0 \\
6.9 \\
103.1 \\
112.7 \\
113\end{array}$ & $\begin{array}{r}2950 \\
98.3 \\
108.1 \\
7.8 \\
103.3 \\
109.6 \\
110\end{array}$ & $\begin{array}{r}312.8 \\
104.3 \\
112.7 \\
8.7 \\
104.0 \\
113.7 \\
114\end{array}$ & $\begin{array}{r}302.0 \\
100.7 \\
113.5 \\
9.5 \\
104.0 \\
113.7 \\
113\end{array}$ & $\begin{array}{r}292.0 \\
97.3 \\
110.4 \\
10.4 \\
100.0 \\
1093 \\
109\end{array}$ & $\begin{array}{l}91.578\left(g^{\prime \prime}\right. \\
1199.58(\xi \\
1200(\xi\end{array}$ \\
\hline
\end{tabular}

AFWIJKINGEN VAN HET MOVIMG-AVERAGE

\begin{tabular}{|c|c|c|c|c|c|}
\hline MAAND & $\begin{array}{l}\text { WERKELUKE } \\
\text { MAAMDVERK. } \\
\text { GELOCALISEEPD } \\
\text { OD DEN ISEN. } \\
\text { (A) }\end{array}$ & $\begin{array}{l}12 \text { MAAND } \\
\text { TOTAAL } \\
\text { GELOCALSEERR } \\
\text { OPDEN 3OEN } \\
\text { (B) }\end{array}$ & $\begin{array}{l}12 \text { MAAND } \\
\text { GEMIDDELDE } \\
\text { GELCALISEERD } \\
\text { OD DEM } 30 \text { OEN } \\
\text { (C) }\end{array}$ & $\begin{array}{l}\text { MOVING } \\
\text { AVERAGES } \\
\text { (D) }\end{array}$ & $\begin{array}{l}\text { AFWIUKING } \\
\text { VAN HET } \\
\text { MOVING } \\
\text { AVERAGE } \\
\text { (E) }\end{array}$ \\
\hline $\begin{array}{l}\text { JAN. 15. } 1919 \text {. } \\
\text { FEBR. } 15 \\
\text { MAART } 15 \\
\text { APRI } 15 \\
\text { MEI } 15 \\
\text { JUNI } 15 \\
\text { JULI } 15 \\
\text { AUE. } 15 \\
\text { SEPT. 15 } \\
\text { OCT. } 15 \\
\text { NOV. } 15 \\
\text { DEC. } 15 \\
\text { JAN. } 15.1920 \\
\text { FERR. } 15 \\
\text { MAART } 15 \\
\text { ADRIL } 15 \\
\text { MEI } 15 \\
\text { JUNI } 15 \\
\text { JULI } 15 \\
\text { ALG. } 15 \\
\text { SEPT. } 15 \\
\text { OCT. } 15 \\
\text { NOV. } 15 \\
\text { DEC. } 15\end{array}$ & $\begin{array}{l}1.176 \\
1.068 \\
1.112 \\
1.333 \\
1.257 \\
1.279 \\
1.335 \\
1.643 \\
1.845 \\
2.264 \\
1.637 \\
2.248 \\
1.729 \\
1.705 \\
2.041 \\
1.644 \\
1.771 \\
1.861 \\
1.896 \\
2.105 \\
2.093 \\
2.015 \\
2.049 \\
1.957\end{array}$ & $\begin{array}{l}18.197 \\
18.750 \\
19.387 \\
20.316 \\
20.627 \\
21.141 \\
21.723 \\
22.284 \\
22.746 \\
22.994 \\
22.745 \\
23.157 \\
22.866 \\
22.029 \\
21.192 \\
20.204 \\
19.417 \\
18.556 \\
17.657\end{array}$ & $\begin{array}{l}1.516 \\
1.562 \\
1.616 \\
1.693 \\
1.719 \\
1.762 \\
1.810 \\
1.857 \\
1.896 \\
1.916 \\
1.895 \\
1.950 \\
1.906 \\
1.836 \\
1.766 \\
1.684 \\
1.618 \\
1.546 \\
1.471\end{array}$ & $\begin{array}{l}(1.203) \\
(1.300) \\
(1.380) \\
(1.430) \\
(1.470) \\
(1.500) \\
1.539 \\
1589 \\
1.655 \\
1.706 \\
1.740 \\
1.786 \\
1.834 \\
1.877 \\
1.906 \\
1.906 \\
1.913 \\
1.918 \\
1.871 \\
1.801 \\
1.729 \\
1.651 \\
1.582 \\
1.508\end{array}$ & $\begin{array}{c}(95.6) \\
(82.2) \\
(80.6) \\
(93.2) \\
(85.5) \\
(85.3) \\
86.8 \\
103.4 \\
111.5 \\
132.7 \\
94.1 \\
125.9 \\
94.3 \\
90.8 \\
107.1 \\
86.3 \\
92.6 \\
97.0 \\
101.3 \\
116.9 \\
121.3 \\
122.0 \\
129.5 \\
129.8\end{array}$ \\
\hline
\end{tabular}

TABEL 5

In tabel 5 hebben de kolommen onderstaande betcekenis:

A. De maandomzetten, gelocaliseerd op den 15den.

B. De „Moving Annual Totals" gèlocaliseerd op den laatsten van de Ge maand.
(.) De gemiddelde maandonzetten, gebascer( op „Moving Anuual Totals'.

I). De moving averages gelocaliseerd op den 15 den (d.w.z. het geniddelde van twee naast-elkaar liggende cijfer's uit kolom (.$)$.

F. Afwijkingen tusschen D. (n A. (d.w.z. de cijfers in kolom A. uitgedrukt in procenten van die in kolom 1).; wanneer men het verschil tusschen het gevonden procent en honderd procent bepaalt, vindt men de afwijking van de moving averages.)

In taljel 5 zijn bij wijze van roorbeeld slechts twee jaren verwerkt. In tabel 6 zict men de eijfers uit kolom E. over 5 jarcn uitgezet. Men sommeert de drie centrale waarden. De uiterste vallen weg om tocvalsfactoren zooveel mogelijk te elimineeren. Hierna bepaalt men het gemiddelde (kolom G.) en corrigeert deze door het totaal der gemiddelden op 1200 te brengen. Hiemee zijn volgens deze methode de seizoen-indices bepald.

\section{VERGELIJKING DER I)RIE ME'THODEN.}

Bij alle methoden moet vooropgesteld worden, dat het slechts doel heeft seizoen-indices te berekenen, wanneer met zekerheid kan worden aangenomen, dat el van seizoen activiteit sprake is. De spleidingstabel (zic tabel 7 ) is een middel, on deze zekcrheid al dan niet te krijgen. In ons voorbeeld zijn de , (tliedziffern" uit methode 2 in deze tabel door streepjes aangegeven. Het kruisje wijst op de hoegrootheid van het rekenkundig gemiddelde der drie centrale ,link-relatives".

\begin{tabular}{|c|c|c|c|c|c|c|c|c|}
\hline \multirow{2}{*}{ MAAND } & \multicolumn{5}{|c|}{ MOVING-AVERAGES (O } & \multirow{2}{*}{$\begin{array}{l}\text { TOTAAL } \\
\text { CENTRALE } \\
\text { WAARDEN } \\
\text { (F) }\end{array}$} & \multirow{2}{*}{$\begin{array}{c}\text { GEMIDDELDE } \\
\text { DER CEMTR } \\
\text { WAARDEM } \\
(G)\end{array}$} & \multirow{2}{*}{$\begin{array}{l}\text { SEIZOEN } \\
\text { INDEX. } \\
(H)\end{array}$} \\
\hline & $\begin{array}{c}1919 \\
\text { (A) }\end{array}$ & $\begin{array}{l}1920 \\
\text { (B) }\end{array}$ & $\begin{array}{l}1921 \\
\text { (c) }\end{array}$ & $\begin{array}{c}1922 \\
\text { (D) }\end{array}$ & $\begin{array}{c}1923 \\
\text { (E) }\end{array}$ & & & \\
\hline JAN. & $(95.6) *$ & 94.3 & $62.2 *$ & 73.8 & 78.7 & 246.8 & & \\
\hline & & $00.8 *$ & & 68.7 & 848 & & 78.6 & 79.6 \\
\hline & $(80.6) *$ & 107.1 & 83.9 & 89.7 & $110.8 *$ & 280.7 & 93.6 & \\
\hline & (93.2) & 86.3 & $73.8 *$ & 91.8 & $104.0 *$ & 271.3 & 90.4 & 91 \\
\hline ME! & $(85.5)$ & 92.6 & $82.3 *$ & $106.0 *$ & 1059 & 284 & 94.6 & 95 \\
\hline JUNI & $(83.3)^{*}$ & 970 & 93.8 & 99.8 & $174.1 *$ & 290.6 & 96.9 & 98.0 \\
\hline JULI & 86.8 & 101.3 & $84.1 *$ & 97.2 & $102.6 *$ & 285.3 & 95.1 & 96.2 \\
\hline AUG. & 103.4 & $116.9 *$ & $99.3 *$ & 115.3 & 102.0 & 320 & 107.0 & 108.1 \\
\hline SEDT. & 111.5 & $121.3 *$ & 114.5 & 107.0 & $997 *$ & 333.0 & 111.0 & 112.0 \\
\hline OCT. & $132.7 *$ & 122.0 & 1233 & $1093 *$ & 176.5 & 36 & & 121 \\
\hline NOV. & $94.7 *$ & $129.5 *$ & 117.2 & 107.2 & 100.5 & 324.9 & 108.3 & 109.5 \\
\hline DEC & 125.9 & $129.8 *$ & $93.6 *$ & 99.1 & 101.7 & 326. & 1089 & 110.0 \\
\hline
\end{tabular}

\% geschrapt TER VERKRUEING VAM Gemiodelden. 
De klassc-intervallen moeten groot of klein zijn, nanrmate de getallen sterk of weing afwijken van 100 . Bij sterke variatie kiest men zelfs intervallen van 5. Men moet net zoolang proheeren, tot het verlooy der maandomzetten duidelijk naar voren komt.

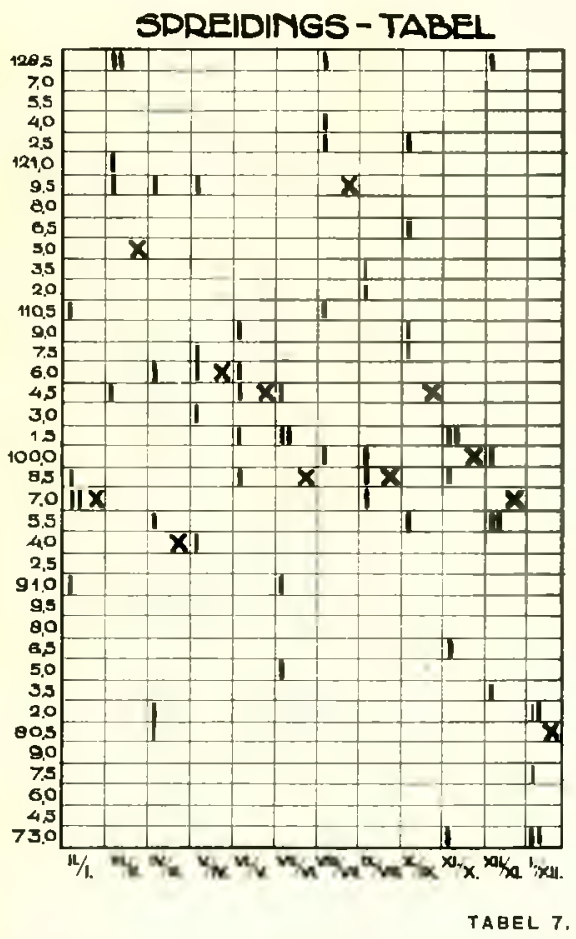

Als alle cijfers dicht on de 100 gegroepeerd $z$ ijn, dan is er geen seizoen-beweging; crenzoo, wanncer zij greheel uit elkaar liggen.

In ons voorteeld blijkt uit de spreidingstabel duidelijk scizoen-beweging.

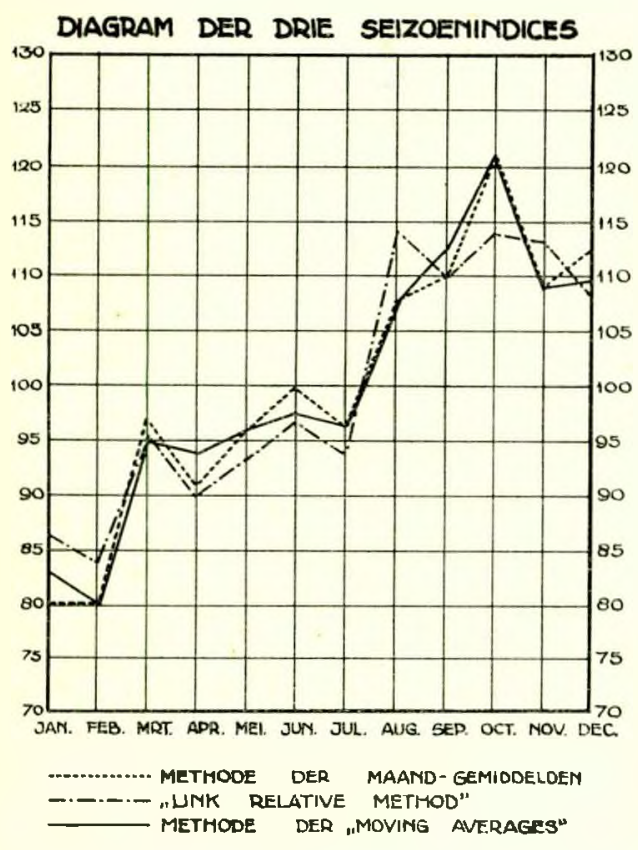

TABEL 8 .

De methode de mandgeniddelden is de eenvoudigste en het is dus aanbevelingswarardig, deze zooveel mogelijk te gebruiken. Wameer cchter de conjunctuurinvloeden al te storend werken, moet men een der beide la atste methoden kiezen. De derde methode heeft het nadeel, de bewerkelijkste te zijn. Naarmate men meer jaren in clen kring der beschouwing betrekt, doet dit nadeel zich des te sterkel voelen. Is er echter sprake van een uitgesproken „Trend" en scherpe conjunctuurbeweging, dan is de derde methode te prefereeren, omdat de vergelijking van elken maandomzet met een meeschuivend maandgemiddelde een beteren maatstaf bicdt voor de bepaling der seizoensbeweging, dan de vergelijking van twee naast elkaar liggende maanden, zooals bij de „link-relative" methode gebeurt. Deze laatste laat zich vooral goed gebruiken bij langere tijdruimten en minder sterk geprononcecrde seizocnshewegingen.

Belangstellenden wordt gewezen op liet ,Journal of the American Statistical Association", speciaal het Septemberlummer van 1928. Hierin komt een artikel voor van Joy \& Thomas, waar an de hand van interessant ejjfermateriaal (de cementproductic der U.S.A.) beide methoden vergeleken worden cn de schrijver's een pleidooi leveren voor het gebruik van de methoden der moving averages.

Drs. J. G. STRIDIRON

\section{LIGT IN DE EFFICIENTIE DE GROND DER WERKLOOSHEID?}

De hecr Blazer merkt in zijn zeer lezenswaard artikel in het Mei-1929-nummer van dit blad over, ,de Efficiencydagen en Ufficiency" o.a. het volgende op :

De toenemende stroom van rationalisatic en normalisatic heeft werkloosheid in rijn slcep. Uit de voordeelen, dic deze efficiente bedrijfsorganisatic brengt, moet het bestaan van groote massa's worden bekostigd, zonder dat daal'voor e'nige arbeid ran hen kan gevrangd worden. Hoe lost men dit vlaagstuk van deze op het oog irrationeele arbeidsverspilling (niet gebluik maken van beschikbare arbeidskracht) op? Men zegt wel, dat de rationalisatie slechts tijdelijke werkloosheid tengevolge heeft, en dat de verlaging van kostprijs naast de verhooging der loonen van gebruikte werkkrachten den levensstandaard van de arbeiders zullen verhoogen, waardoor vele werkkrachten op nieuwe gebieden (auto- en radio-industrie, onderwijs aan stecds grootere groepen) werk zullen vinden, maal dit zal alleen opgan en stand houden als er een eind is gekomen aan de rationalisatic door hare volmaking, en als er geen nicuwe machines on werkwijzen meer worden nitgeronden."

De schrijver pakt hier aan cen probleem van den eersten rang, zoowel in de theoretische als in de practische cconomie, dat der werkloosheid. Strikt genomen kan men zeggen, dat dit onderwerp niet tot het terrein van dit blad behoort, doch de heer Blazer bewijst klaarlijk, dat "de grens nergens is". dat men op de meest natumlijke wijze van het eene gebied op het andere overgant; aan de grens is het een en het ander hetzclfde, en zoo blijkt ook de grens, tie het blad zichzelf stelde, cen willekeurige grenslijn te zijn. Het zijn toch de arbeiders uit de bedrijven; en zijn het niet de ondernemers, die hen op de markt werpen of hen er wecr afnemen?

De wcrkloosheid is cen verschijnsel van het bedrijfsleven, ran het leven als bedrijf. Dat dit onderwerp buiten behandeling blijft in bladen als dit, valt daaruit te verklaren, dat de beschouwer van het bedrijf den werklooze daar niet ontmoet. Ilij ralt daar buiten en nu komt de bedrijfshuishoudkundige in den waan, dat hij niets met hem te maken heeft. Dat is echter maar schijn, want hij bepaalt mede het loon door het te drukken en hij vermindert bovendien den afzet.

Indien ik dus de vraag: is dit wel juist, die bij mij rees bij het lezen van het door mij aangehaalde gedeclte van het artikel ran den heer Blazer, hiel tracht te beantwoorden, dan moge dit geen verwondering wekken.

Tel voorkoming van mogelijk misvelstand zij hier terstond 